\title{
Design and Formulation Technique of a Novel Drug Delivery System for Azithromycin and its Anti-Bacterial Activity Against Staphylococcus aureus
}

\author{
M. Joyce Nirmala, ${ }^{1}$ Amitava Mukherjee, ${ }^{1}$ and N. Chandrasekaran ${ }^{1,2}$
}

Received 4 March 2013; accepted 11 June 2013

Abstract. Azithromycin, an important member of the azalide subclass is effective against both Grampositive and Gram-negative organisms. Certain physicochemical properties of the drug like poor water solubility and relatively low bioavailability of $37 \%$ due to incomplete absorption after ingestion, aroused the need for the development of a novel drug delivery system to enhance the solubilization potential and antibacterial activity against Staphylococcus aureus at a very low concentration. Cinnamon oil (Cinnamonum zeylanicum)-based microemulsion system formulated using non-ionic surfactant, Tween 20, and water was characterized. The drug-incorporated system F4 (oil to surfactant ratio of 1:4 (v/v)) showed enhanced solubilization of the drug, droplet diameter of 5-8 $\mathrm{nm}$, and a good thermodynamic stability. The effect of surfactant concentration exhibited a negative correlation with droplet size diameter and turbidity and a positive correlation with stability and viscosity. The system was investigated for its antibacterial activity that demonstrated a significantly higher activity at a minimum concentration $(4 \mu \mathrm{g} /$ $\mathrm{ml}$ ) of the novel drug-loaded system in comparison with the conventional formulation $(128 \mu \mathrm{g} / \mathrm{ml})$. Examination through scanning electron microscopy analysis further confirmed a considerable morphologic variation due to alteration in the membrane permeability of the microemulsion-treated system. The small droplet size of the microemulsion system and the antibacterial property of cinnamon oil, together, accounts clearly for the enhanced efficacy of the new formulated system F4 and not just azithromycin alone. Staining with acridine orange/ethidium bromide dyes as examined through fluorescence microscopy also substantiated with the results of membrane permeability of bacteria. Thus, our study discloses a potential oral drug delivery system of azithromycin with improved biocompatibility.

KEY WORDS: antibacterial activity; azithromycin; cinnamon oil; fluorescence; thermodynamic stability.

\section{INTRODUCTION}

Macrolides are a group of drugs that belong to the family of commonly used antibiotics of clinical importance. Generally, macrolides are effective in treating infections caused by Gram-positive organisms like Staphylococcus aureus, Streptococcus pyogenes, and Streptococcus pneumoniae. Staphylococci are responsible for a wide variety of skin infections that may be localized, diffused, or located deep inside and many others (1). But there are certain reports explaining the resistance of $S$. aureus and S. epidermidis to certain antimicrobial agents like methyl penicillin and its derivatives, which in turn, had evolved as a major reason for the development of the secondgeneration antibiotics (2). Azithromycin, of its kind, exhibited significant antibacterial activity against both Gram-positive and Gram-negative (3) organisms. Azithromycin belongs to the subelass of azalides (4) with increased acid stability and their antibacterial activity is due to the presence of a 15membered aglycone ring with additional nitrogen in its chemical structure (5-8). It works by binding to 50S subunit of the

\footnotetext{
${ }^{1}$ Centre for Nanobiotechnology, VIT University, Vellore 632-014, Tamil Nadu, India.

${ }^{2}$ To whom correspondence should be addressed. (e-mail: nchandrasekaran@vit.ac.in)
}

$70 \mathrm{~S}$ bacterial ribosome and also interferes with the elongation of nascent polypeptide chain, thus, inhibiting the RNA dependent protein synthesis in susceptible micro-organisms (9). Azithromycin, though similar to erythromycin, shows improved potency against infections caused by Hemophilus influenzae, S. pneumoniae, Clamydophila pneumoniae, Mycoplasma pneumoniae, Moraxella catarrhalis, S. aureus, S. pyogenes, Salmonella typhi, and others $(10,11)$. The potency is mainly attributable to the modification in the chemical structure of azithromycin. But there has been problem regarding the emergence of more resistant strains due to the extensive usage of antibiotics by patients without the prescription by doctors. Moreover, azithromycin was found to be highly lipophilic with poor water solubility and relatively low oral bioavailability of $37 \%$ after ingestion (12). Acid degradation of the drug before absorption and possibly, incomplete absorption accounts for low bioavailability (13). Hence, a need arouses to improve the antibacterial efficacy by designing a more effective and a suitable drug delivery system for azithromycin and to monitor the in vitro susceptibility of the organism.

The concept of microemulsion has drawn attention as drug delivery agents due to the presence of compartmentalized hydrophilic and hydrophobic domains in which both nonpolar and polar compounds could be incorporated. Oil-in- 
water microemulsions are generally preferred in improving the bioavailability of highly lipophilic and aqueous insoluble drugs (14-17). The microemulsion technique is prepared in ease (with no input of high-energy methods) and provides very low interfacial tension at the oil/water interface, greater solubilization of organic compounds, small droplet size, high surface area, enhanced shelf life, and good thermodynamic stability (18-22). All these factors enable easy permeation of drugs through small capillary vessels without any discrimination by the host natural defense mechanism and therefore, readily absorbed by the organs presenting improved therapeutic efficacy $(23,24)$.

In recent years, there are many findings related to essential oil-based microemulsion system having prospective applications in pharmaceuticals (25-29). This includes clove oil microencapsulation of natural bioactive products like Bassic acid, Quercetin, and Diospyrin that is reported to be more efficient, nontoxic, and biocompatible as well (30-32). In our study, we initially assessed the highest solubilization capacity in order to reduce the dosage concentration and also to improve the efficacy of the novel formulated drug delivery system against bacteria. Hence, we aimed at designing and characterizing biologically acceptable novel cinnamon oil-based microemulsion system as drug delivery vehicle for azithromycin with minimum components in them. Cinnamon oil, chosen in this study, is known to possess diverse functions including analgesic, antiallergic, antidiabetic, antimicrobial, antioxidant, antipyretic, antispastic, antithrombotic, antiulcerogenic, anxiolytic, and antiulcerous effects (33-38). Also, Cinnamomum zeylanicum has eugenol and transcinnamaldehyde as the major components in them (39). Hence, the potential activities of these volatile compounds play a role in enhancing the biological applications of the cinnamon oil. The drug-incorporated novel microemulsion system was tested for its efficacy against S. aureus (ATCC 25923). The membrane integrity of bacteria and fluorescent microscopic techniques were used in studying the effects of the newly formulated azithromycin in comparison with the conventional formulation.

\section{MATERIALS AND METHODS}

\section{Materials}

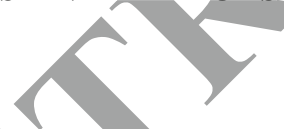

Azithromycin was a kind gift sample from Aurobindo Pharma Limited, Hyderabad, India. Cinnamon leaf oil (extracted from C. zeylanicum), nonionic surfactant Tween 20, and acridine orange were obtained from Sigma Aldrich, India. Castor oil, eucalyptus oil, and peppermint oil was obtained from Hi Media Laboratories, Mumbai, India. Coconut oil was obtained from the local market in Vellore, India. Ethidium bromide was supplied by Medox Biotech India Pvt. Ltd. Ultrapure water (CascadaTM Biowater System, Pall Corporation, USA) with a resistivity of not less than $18.2 \mathrm{M} \Omega \mathrm{cm}$ was used throughout the study for all experiments. The antibacterial activity carried out using S. aureus (ATCC 25923) was purchased from Hi Media. All other reagents used were of analytical reagent grade.

\section{Screening of Oils for Microemulsion}

The solubility of azithromycin in different oils (castor oil, coconut oil, eucalyptus oil, peppermint oil, and cinnamon oil) was determined by conventional equilibration method by adding an excess amount of drug to $3 \mathrm{ml}$ of the selected oils in 5 -ml capacity stopper vials. The mixture was vortexed and kept in an orbital shaker (Orbitek Pilot Shaker Model PX1, Scigenics Biotech, India) for $72 \mathrm{~h}$ and maintained at a temperature of $25 \pm$ $1.0^{\circ} \mathrm{C}$ to reach equilibrium. The equilibrated samples were then centrifuged at 3,000 rpm for $15 \mathrm{~min}$ and the supernatant was filtered through a $0.45-\mu \mathrm{m}$ membrane filter. The drug concentration in the filtrate was determined using double-beam UVvisible spectrophotometer (UV-Vis Systronics-2201) after appropriate dilution (40) with methanol at $215 \mathrm{~nm}$.

\section{Preparation of Drug-Loaded Microemulsion}

A minimum amount of $10 \mathrm{mg}$ of the lipophilic drug, azithromycin, was dissolved in $1 \mathrm{ml}$ of cinnamon oil and kept overnight to ensure complete dissolution. Followed by addition of surfactant and water that is thoroughly mixed using vortex for the incorporation of drug in the oil-in-water microemulsion system. The drug is water insoluble and thus remains in the oil core.

Thus, a microemulsion system was formulated using cinnamon oil as the oil phase, Tween 20 (with average HLB value of 16.7) as the non-ionic surfactant, and water as the aqueous phase. Tween 20, a small molecule surfactant gets adsorbed onto emulsion droplet surface more rapidly than high molecular weight surfactants (e.g., polymers). Thus, Tween 20 is comparatively more effective in minimizing droplet diameter than polymers. The concentration of cinnamon oil $(6 \% v / v)$ was fixed for all formulations. Organic phase was prepared by mixing oil and surfactant in different ratios $(v / v)$ such as $1: 1$, $1: 2,1: 3,1: 4$, and 1:5 (Table I) and then organic phase was drop-wise added to water. The reaction was carried out by gentle agitation or mixing of the components. Emulsions were formed spontaneously and characterized.

\section{Physicochemical Characterization}

\section{Viscosity Measurements}

Viscosity of all the formulated drug-loaded microemulsions was measured using a Brook Field Viscometer (model LVF

Table I. Composition of Different Components of Cinnamon OilBased Formulations

\begin{tabular}{ccccc}
\hline & \multicolumn{4}{c}{$\begin{array}{l}\text { Percent composition of } \\
\text { different components }\end{array}$} \\
\cline { 3 - 5 } $\begin{array}{l}\text { Formulation } \\
\text { code }\end{array}$ & $\begin{array}{l}\text { Oil/surfactant } \\
(v / v)\end{array}$ & Cinnamon oil & Tween 20 & Water \\
\hline F1 & $1: 1$ & 6 & 6 & 88 \\
F2 & $1: 2$ & 6 & 12 & 82 \\
F3 & $1: 3$ & 6 & 18 & 76 \\
F4 & $1: 4$ & 6 & 24 & 70 \\
F5 & $1: 5$ & 6 & 30 & 64 \\
\hline
\end{tabular}


69726) supplied with UL adapter. All the experiments were performed at $25^{\circ} \mathrm{C}$ and in triplicates.

\section{Turbidity Measurements}

Turbidity of the formulated drug-loaded microemulsions was analyzed by measuring the absorbance at $600 \mathrm{~nm}$. Absorbance of undiluted samples at $600 \mathrm{~nm}$ was recorded using UV-visible spectrophotometer (2201, Systronics, India).

\section{Size Analysis}

\section{Droplet Size Distribution of the Drug-Loaded Microemulsion}

Droplet size and polydispersity index of F4 microemulsion formulation (drug loaded) was determined using 90 plus particle size analyzer (Brookhaven Instruments Corporation, Holtsville, NY, USA). Microemulsion formulation was diluted with ultrapure double-distilled water prior to experiment to do away with the effect of viscosity caused on account of emulsion ingredients and also to trim down multiple scattering effect. The size measurement was carried out in triplicates and the average results were reported in this paper. A sample volume of $3 \mathrm{ml}$ was used in these measurements.

\section{Thermodynamic Stability Studies}

The stability of the drug-loaded microemulsions during storage at room temperature and under extreme conditions was examined as follows:

\section{Centrifugation Study}

The formulated microemulsions were studied for their resistance to centrifugation. To ensure physical stability, all formulations were subjected to centrifugation (REMI International, India) at 3,500 rpm for $30 \mathrm{~min}$ and observed for phase separation, creaming, and cracking (if any).

\section{Heating-Cooling Cycle}

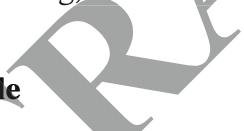

This study was performed to check the effect of temperature variations on the stability of microemulsion formulations. Samples were stored between $4^{\circ} \mathrm{C}$ and $45^{\circ} \mathrm{C}$ temperature each for a period of $48 \mathrm{~h}$. The heating-cooling cycle was repeated six times. The microemulsion formulations that did not show any instability (such as cracking, creaming, and phase separation) were chosen and subjected to freeze-thaw stress.

\section{Freeze-Thaw Cycle}

In this study, microemulsion formulations were subjected to freeze-thaw cycle between $-21^{\circ} \mathrm{C}$ and $+25^{\circ} \mathrm{C}$ with storage at each temperature for a minimum period of $48 \mathrm{~h}$. Three freeze-thaw cycles were performed and the formulations that are stable to this stress condition was further selected and characterized for study.

\section{Kinetic Stability}

Microemulsion formulations were preserved at room temperature for checking out intrinsic stability. The emulsion formulations were observed for phase separation, creaming, and cracking with respect to prolonged storage time period. Kinetic stability was investigated by measuring droplet size of the microemulsions in different intervals of time.

\section{Drug Content in the Microemulsion System (F4)}

For determination of drug content, about $1 \mathrm{ml}$ of the drug-loaded microemulsion system (F4) was measured and this was diluted appropriately using ethanol and the drug content was determined spectrophotometrically at $215 \mathrm{~nm}$.

\section{Antibacterial Activity}

\section{Preparation of Inoculum}

The stock strain of S. aureus (ATCC 25923) was maintained on nutrient agar slopes at $4{ }^{\circ} \mathrm{C}$. For the experiments, a loopful of colonies were inoculated into MuellerHinton broth (MHB) and incubated for $18-24 \mathrm{~h}$ at $35^{\circ} \mathrm{C}$. A repeat subculture was made to ensure purity and viability. The culture was then diluted with fresh MHB to achieve optical densities corresponding to $1.5 \times 10^{7}-10^{8}$ colony forming units (CFU/ml).

\section{Preparation of Drug Stock Concentrations}

Azithromycin bulk formulation was prepared by dissolving azithromycin pure in ethanol and diluted using sterile ultrapure water (41). Azithromycin in cinnamon oil alone was also studied by dissolving azithromycin in cinnamon oil and $10 \%$ DMSO was used as the diluent. Azithromycin microemulsion formulation was prepared by dissolving azithromycin pure in cinnamon oil microemulsion formulation. Sterile ultrapure water was used as the diluent.

The stock concentrations of $1,000 \mu \mathrm{g} / \mathrm{ml}$ were prepared initially for bulk and microemulsion formulations separately. From the stock concentrations, various dilutions of $0.25,0.5,1$, $2,4,8,16,32,64,128,256$, and $512 \mu \mathrm{g} / \mathrm{ml}$ were prepared for determining the susceptible zone range.

\section{Antibacterial Susceptibility Testing}

The antibacterial activity was screened by paper disk diffusion method (42-44) using Mueller-Hinton agar (MHA) medium. About 20-25 ml volume of the molten MHA medium was poured onto sterile Petri plates. The plates were allowed to settle for $5 \mathrm{~min}$. Of the inoculum, $100 \mu \mathrm{l}$ was swabbed uniformly onto the plates and allowed to dry. About $10 \mu \mathrm{l}$ of different concentrations ranging from 0.25 to $512 \mu \mathrm{g} /$ $\mathrm{ml}$ of both azithromycin bulk and azithromycin microemulsion formulation were loaded onto 6-mm sterile disk, respectively. The loaded disk was then placed on the surface of medium and allowed to diffuse for few min. For control, a $15 \mu \mathrm{g}$ azithromycin disk (Hi Media) was placed separately onto a plate. The plates are incubated at $37^{\circ} \mathrm{C}$ for $18-24 \mathrm{~h}$. The sensitive zone was measured in millimeters using horizontal 
ruler. The studies were carried out in triplicates to ensure reproducibility.

\section{Determination of Minimal Inhibitory Concentration by Broth Microdilution Technique}

The minimal inhibitory concentrations (MICs) were determined for both conventional and microemulsion formulation of azithromycin by microwell dilution technique using Mueller-Hinton broth. The inoculum used was a suspension of microorganisms ( $S$. aureus) of $1.5 \times 10^{7}-10^{8} \mathrm{CFU} / \mathrm{ml}$. Both the formulations were dissolved in sterile ultrapure water to the highest concentration to be tested $(512 \mu \mathrm{g} / \mathrm{ml})$ and then serial twofold dilutions were made in concentrations ranging from 512 to $0.25 \mu \mathrm{g} / \mathrm{ml}$. The 96-well microplates were prepared by dispensing into each well $95 \mu \mathrm{l}$ of culture broth, $5 \mu \mathrm{l}$ of inoculum, and $100 \mu \mathrm{l}$ serial dilutions $(512-0.25 \mu \mathrm{g} / \mathrm{ml}$ ) of both conventional and cinnamon oil-based microemulsion of azithromycin, respectively. The final volume in each well was $200 \mu \mathrm{l}$. The plates were incubated at $37^{\circ} \mathrm{C}$ for $24 \mathrm{~h}$ and read visually. MIC was defined as the lowest concentration at which there was no viability or visible growth after the incubation period. A microbial culture control (a series of wells containing culture medium with microbial suspension) and a sterility control (a series of wells containing only culture medium) were also used in this technique. The test was performed in triplicates (45-47).

\section{Membrane Integrity of Bacteria}

The membrane integrity test was performed with optimized minimal concentration of the treated culture ( $\delta$. aureus, $4 \mu \mathrm{g} / \mathrm{ml}$ ) according to the protocol developed by Hou et al. (48) with a slight modification. An overnight bacterial culture grown at $37^{\circ} \mathrm{C}$ was harvested, washed, resuspended, and adjusted to $1.5 \times 10^{8} \mathrm{CFU} / \mathrm{ml}$ with phosphate buffered saline (PBS). About $0.5 \mathrm{ml}$ of the bacterial culture was diluted with $9.5 \mathrm{ml}$ of optimized concentration of azithromycin bulk (test 1 ) and azithromycin microemulsion (test 2) formulation, respectively. The untreated bacterial suspension diluted with PBS acts as the control. The samples were then incubated at room temperature for $1 \mathrm{~h}$ and centrifuged at $6,000 \times g$ for $10 \mathrm{~min}$, in order to study the release of cytoplasmic contents from bacterial cells. The supernatant obtained was measured for absorbance at $260 \mathrm{~nm}$ using UV-vis spectrophotometer (Systronics 2201, India). The absorbance measured was directly proportional to cytoplasmic leakage of the contents. The results obtained were calculated as mean \pm SD.

\section{Determination of Cell Viability by Acridine Orange/Ethidium Bromide Staining}

The extent of membrane disintegration of $S$. aureus after being treated with both conventional and microemulsion formulation of azithromycin (including untreated control) was demonstrated by acridine orange/ethidium bromide staining. Necrotic and apoptotic cells were distinguished from normal live bacteria cells using ethidium bromide and acridine orange vital dyes by fluorescent microscopy. The fluorescent dye staining technique was performed according to the protocol developed by Jakopec et al. to distinguish live and dead cell cultures after treatment (49). Acridine orange is a vital dye that will stain both live and dead cells, but ethidium bromide will stain only those cells that have lost their membrane integrity. An overnight-grown bacteria culture was harvested by centrifuging at 5,000 rpm for $15 \mathrm{~min}$. A known concentration of the culture inoculum $\left(1.5 \times 10^{7}-10^{8} \mathrm{CFU} / \mathrm{ml}\right)$ was interacted with the determined optimized $4 \mu \mathrm{g} / \mathrm{ml}$ concentration of conventional (test 1) and microemulsion (test 2) formulation of azithromycin, respectively, for a period of $120 \mathrm{~min}$. The pellet-containing bacteria was obtained by centrifuging at $5,000 \mathrm{rpm}$ for $15 \mathrm{~min}$, followed by washing with PBS twice. To about $500 \mu \mathrm{l}$ of the bacterial suspension in PBS, $4 \mu \mathrm{l}$ each of acridine orange $(15 \mu \mathrm{g} / \mathrm{ml}$ of PBS) and ethidium bromide $(50 \mu \mathrm{g} / \mathrm{ml}$ in PBS $)$ were added. After incubating for $5 \mathrm{~min}$, centrifugation was done to get rid of unbound dyes and the pellet was resuspended in $500 \mathrm{ml}$ of PBS ( $\mathrm{pH} 7.4$ ). The images were captured by using fluorescénce microscope (Leica, DM2500) supplied with Leica-DFC-295 camera and LeicaApplication Suite 3.8 processor.

Assessment of Morphological Alterations by Scanning Electron Microscopy

An overnight culture of $S$. aureus grown in 50-ml nutrient broth was incubated at $35^{\circ} \mathrm{C}$ in a rotary shaker at $200 \mathrm{rpm}$. The cells were centrifuged at 5,000 rpm for $15 \mathrm{~min}$ and washed two times in PBS. A known concentration of the culture inoculum $\left(1.5 \times 10^{7}-10^{8} \mathrm{CFU} / \mathrm{ml}\right)$ was prepared, which acts as the control. An optimized concentration $(4 \mu \mathrm{g} / \mathrm{ml})$ of both azithromycin bulk and azithromycin microemulsion formulation was interacted with culture for $120 \mathrm{~min}$. After treatment of $S$. aureus cells with both formulations, the samples were washed twice with PBS ( $\mathrm{pH} 7.4)$ to purge the presence of the test materials. These specimens were mounted on aluminum stubs, followed by coating with gold using a sputter coater. After processing, samples were observed under a high-resolution scanning electron microscope (FEI Quanta FEG 200) that has a resolution of $1.2 \mathrm{~nm}$ gold particle separations on a carbon substrate.

\section{RESULTS}

\section{Criteria for Selection of Components}

For the development of improved oral drug delivery system for azithromycin, various components are chosen from generally regarded as safe (GRAS) category. Oil-in-water microemulsion system is most preferred for the incorporation of hydrophobic drug molecules as they enhance the solubilization and stabilization of the compound and thereby provide a better dissolution in vivo. Hence, lipophilic systems are chosen for our study. Due to minor or no toxic effects of the biobased non-ionic surfactants as compared to ionic surfactants, they are added to our system. Also, the concentration of surfactant used is kept under control as increase may lead to gastrointestinal irritation.

\section{Solubility Study}

The drug is incorporated in the oil core and thus the oil system plays a major role in maintaining the drug compound 
in its solubilized state. Solubility studies are performed to find the solubilization potential of azithromycin in different oil system and the reports are shown in Table II.

\section{Physicochemical Characterization of the Formulations}

By varying oil to surfactant ratio of $1: 1$ to $1: 5$ (F1 to F5), different drug-loaded cinnamon oil-based formulations were formulated to optimize the best formulation with $0.4 \%$ of azithromycin in it. All the formulations were characterized for their droplet size diameter, viscosity and turbidity measurements, and stability studies. From these characterization studies, the best drug-loaded formulation alone was chosen for further in vitro antibacterial activity against $S$. aureus.

\section{Effect of Surfactant Concentration on Droplet Size}

Drug-loaded cinnamon oil-based microemulsion formulations F1, F2, and F3 exhibited droplet diameter of 9,236, 8,923 , and 4,893 nm, respectively. As the surfactant concentration increased, gradual reduction in droplet was observed. Oil to surfactant ratio of 1:4 $(v / v)$ showed droplet size range of $5.2-7.2 \mathrm{~nm}$ (Fig. 1). With further increase in oil to surfactant ratio, no significant decrease in droplet size was obtained. Also, the F4 formulation showed the lowest polydispersity index of 0.058 that confers higher stability than other formulations. The polydispersity index measurement confers homogeneity and stability of the formulations. The lower the polydispersity index, the more stable is the microemulsion formed (50,51). Hence, F4 formulation was chosen for further characterization and application studies.

\section{Effect of Surfactant Concentration on Viscosity}

The surfactant concentration of all the formulated drugloaded formulations exhibited a positive correlation with the viscosity readings (Fig. 2). The viscosity of the formulations F1, F2, F3, F4, and F5 are 2.0, 3.0, 6.2, 20.0, and $25.6 \mathrm{cPs}$, respectively. With increase in surfactant concentration from F1 to F5 (keeping the oil concentration constant), steady increase in viscosity of the microemulsion was observed. All readings were taken in triplicates.

\section{Effect of Surfactant Concentration on Turbidity}

The surfactant concentration of the formulations F1 to F5 exhibited a negative correlation with the turbidity readings. Visual appearances of all the drug-loaded formulations are

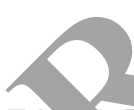

Table II. The Solubility of Azithromycin (mean $\pm \mathrm{SD}, n=3)$ in Various Components

\begin{tabular}{lc}
\hline Components & Solubility $(\mathrm{mg} / \mathrm{ml})$ \\
\hline Castor oil & $4.18 \pm 0.04$ \\
Coconut oil & $3.01 \pm 0.06$ \\
Eucalyptus oil & $0.66 \pm 0.03$ \\
Peppermint oil & $12.57 \pm 0.46$ \\
Cinnamon oil & $64.41 \pm 1.34$ \\
Tween 20 & Not soluble \\
\hline
\end{tabular}

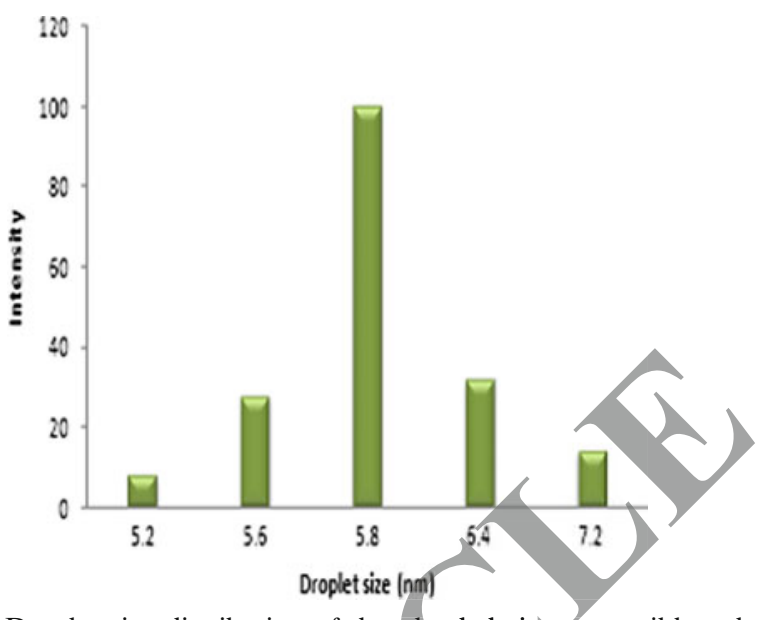

Fig. 1. Droplet size distribution of drug-loaded cinnamon oil-based microemulsion (F4) as determined by DLS

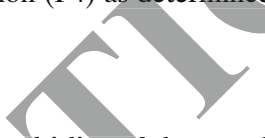

shown in Fig. 3a. The turbidity of the emulsions was expressed as absorbance at $600 \mathrm{~nm}$. Increase in surfactant concentration is seen with reduced absorbance value (Fig. 3b).

\section{Stability of the Drug-Loaded Formulations}

The thermodynamic stability of the formulated drugloaded cinnamon oil-based microemulsions was investigated by subjecting to centrifugation, heating-cooling cycle, and freeze-thaw cycle. Phase separation occurred in F1 and F2 formulations after $24 \mathrm{~h}$ of preparation whereas $\mathrm{F} 3$ formulation separated into constituent phases after $48 \mathrm{~h}$. F3, F4, and F5 were stable after centrifugation, whereas phase separation was observed in case of F1 and F2 formulations. F4 and F5 formulations were stable to temperature variation and sustained after freeze-thaw and heating-cooling cycle. F1, F2, and F3 formulations did not withstand extreme temperature changes. The kinetic stability of the formulations was studied by storing for prolonged periods of time. Both F4 and F5 formulations

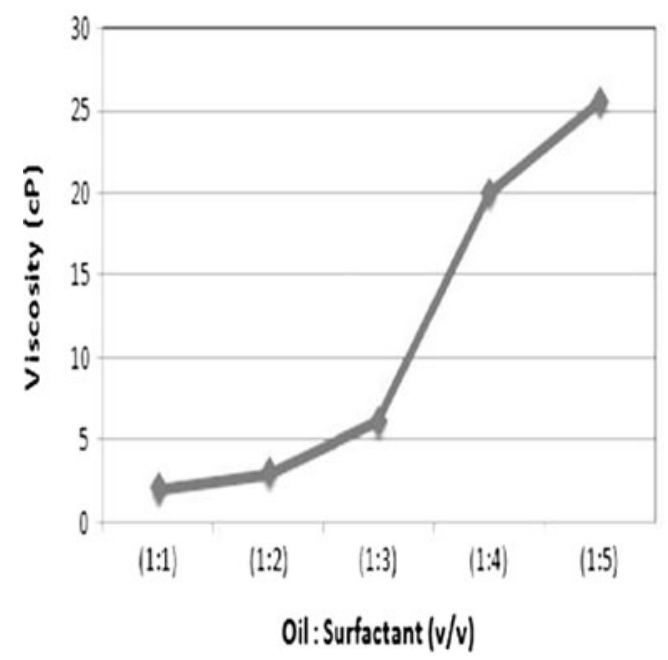

Fig. 2. The effect of surfactant concentration has a positive correlation on the viscosity of formulations F1 to F5 
a

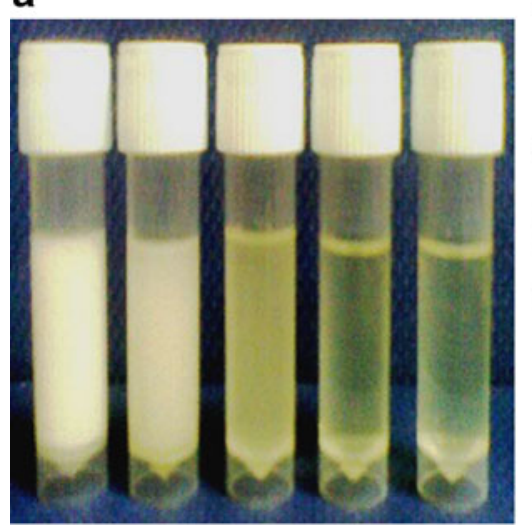

b

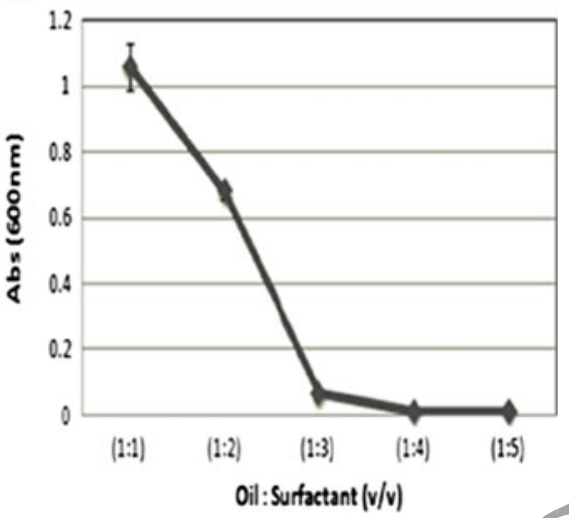

Fig. 3. a Visual appearance of the formulations F1 to F5 (milky white to transparent). b The effect of surfactant concentration has a negative correlation on the turbidity of F1 to F5 formulations

demonstrated good kinetic stability of 8 months. Owing to the less surfactant concentration of F4 compared to F5, the droplet size of $\mathrm{F} 4$ formulation was measured in different intervals of time that did not show any significant change under prolonged storage (Fig. 4).

\section{Drug Content in the Microemulsion (F4)}

The azithromycin content in our new formulated system was found to be $98.67 \pm 0.98 \%$ of the theoretical value $(0.4 \%$ $w / v)$. This parameter is necessary for determining the dosage of the antibiotic.

\section{Antibacterial Activity}

\section{Antibacterial Susceptibility Testing}

The antibacterial activity was performed against $S$. aureus (ATCC 25923). Azithromycin pure was prepared at varying

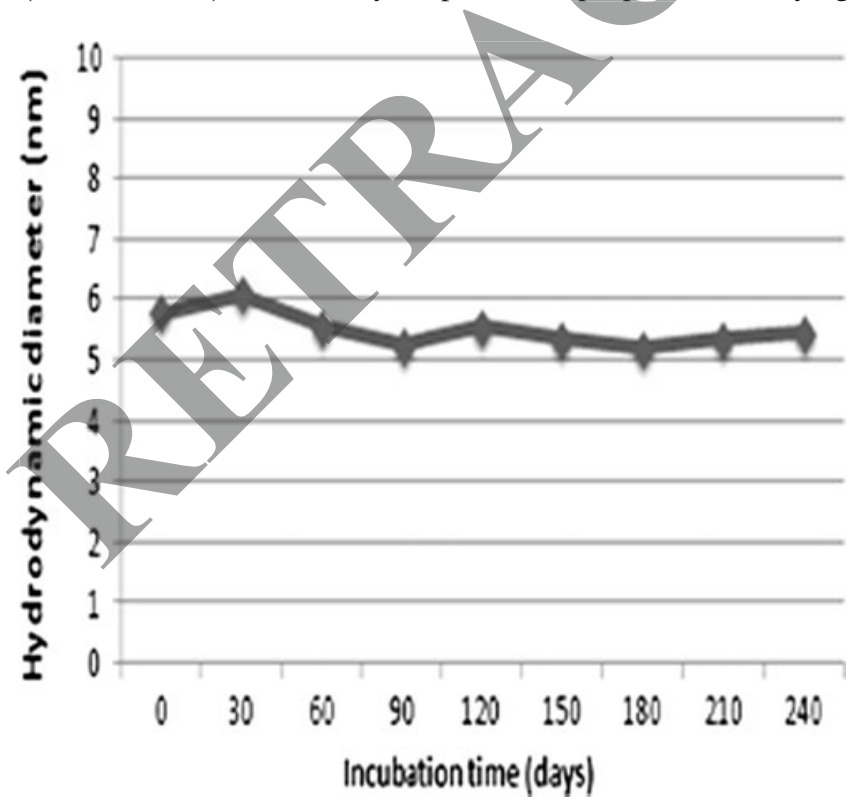

Fig. 4. Kinetic stability of the drug-loaded cinnamon oil microemulsion formulation (F4) concentrations of $0.25,0.5,1,2,4,8,16,32,64,128,256$, and $512 \mu \mathrm{g} / \mathrm{ml}$ for both conventional formulation (sterile water used as diluent), cinnamon oil alone formulation (10\% DMSO used as diluent), and cinnamon oil-based microemulsion formulation (sterile water used as diluent), respectively. The quality control strain of $S$. aureus gave 21-26 mm zone sizes with $15 \mu \mathrm{g}$ azithromycin disk. And thus for the interpretation of tests, $\geq 19 \mathrm{~mm}$ was considered as susceptible and $\leq 15 \mathrm{~mm}$ was considered as resistant (52). The sensitive zone of inhibition was obtained at $128 \mu \mathrm{g} / \mathrm{ml}$ for conventional formulation and $64 \mu \mathrm{g} / \mathrm{ml}$ for cinnamon oil formulation of azithromycin alone, respectively. A blank microemulsion excluding the drug was also used, for which the zone of inhibition was obtained at $64 \mu \mathrm{g} / \mathrm{ml}$. In the case of microemulsion formulation of azithromycin, a superior inhibition activity was obtained at a minimum concentration of $4 \mu \mathrm{g} / \mathrm{ml}$.

\section{Quantitative Assay for Antibacterial Activity by Broth Microdilution Method}

The quantitative method for determining antibacterial activity of both conventional and microemulsion formulations of azithromycin were done by microdilution method in liquid medium. The MIC value was read by visual observation of wells: in the initial wells containing high concentrations of both formulations of azithromycin, there was no visible culture growth. This means that all microbial cells are killed or inhibited at this highest concentration. At lower concentrations of both drugloaded formulations, the microbial culture growth was visible. The least or minimum concentration that inhibited the visible microbial growth was considered as the MIC (in microgram per milliliter) value for the tested compounds, respectively. Thus, the MIC value was found to be 128 and $4 \mu \mathrm{g} / \mathrm{mL}$ for conventional and microemulsion formulation of azithromycin respectively. Thus, our formulation showed significantly higher antibacterial activity at a very low concentration. The results also correlated well with the abovementioned experiment. The controls in the other wells, including the standard culture growth control wells, the medium appeared very turbid or muddy as a result of microbial growth. In the sterility control wells series, the medium remained clear. From all the concentrations, highest (well without any visible microbial growth) to lowest (well that 


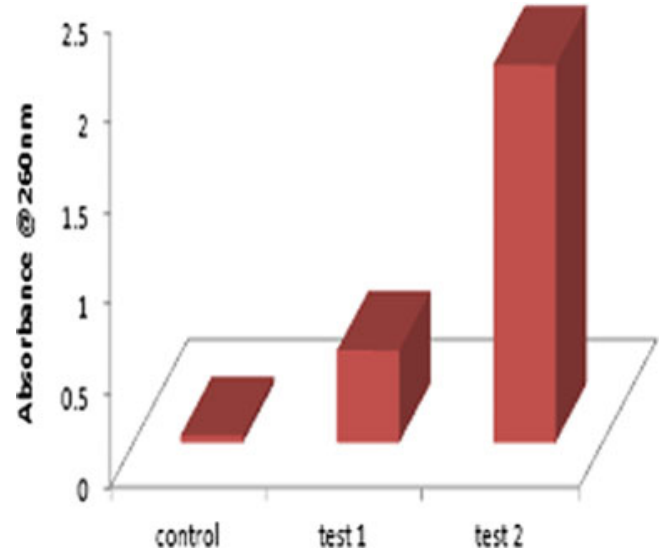

Fig. 5. Comparison of alteration in membrane permeability of both conventional (test 1)- and microemulsion (test 2)-treated cells by the leakage of UV absorbing substances at $260 \mathrm{~nm}$ against $S$. aureus

presented microbial growth) concentration, Gram-stained smears were performed for the results confirmation.

\section{Membrane Integrity of Bacteria}

The cytoplasmic release from the membrane cells of $S$. aureus when interacted with both conventional and microemulsion formulation of azithromycin was quantified by measuring the absorbance at $260 \mathrm{~nm}$. The cytoplasmic leakage observed at $1 \mathrm{~h}$ was $0.51 \mathrm{a}$.u. for conventional formulation (test 1) and 2.08 a.u. for microemulsion formulation (test 2) at $4 \mu \mathrm{g} / \mathrm{ml}$ optimized concentration as obtained from susceptibility testing. From Fig. 5, it is evident that there is tremendous increase in the release of cytoplasmic contents from cinnamon oil-based microemulsion formulation of azithromycin as when compared to conventional formulation.

\section{Determination of Cell Viability by Acridine Orange/Ethidium Bromide Staining}

The cell viability and alteration in membrane permeability of the treated bacteria was substantiated with acridine orange/ethidium bromide staining experiment. Untreated control cells of $S$. aureus (Fig. 6a) were live and appeared apple green in color which is attributable to staining with acridine orange. On treatment of S. aureus (Fig. 6b) with conventional formulation of azithromycin (optimized concentration, $4 \mu \mathrm{g} / \mathrm{ml}$ ), almost all cells were green in color due to their resistance to treatment at this concentration. On treatment of $S$. aureus (Fig. 6c) with same optimized concentration of cinnamon oil-based microemulsion formulation of azithromycin, the cells were all red in color signifying damaged cells with compromised cell membrane. That is, all bacteria cells were killed on treatment with particular concentration of novel microemulsion formulation. Thus, fluorescence microscopy helps a major role in discriminating between live and dead bacteria cells. This technique plays an important role in various medical applications too (53). Also, we obtained similar kind of results in another study, in that we reported, acridine orange responsible for green color stains both live and dead cells. And, ethidium bromide responsible for red color stains only dead cells (54).

\section{Assessment of Morphological Alterations by Scanning Electron Microscopy}

Microscopy is a vital contrivance to study possible deformation in bacterial cell structure and alteration in the surface morphology of micro-organisms due to cell damage (55). On treatment of $S$. aureus with conventional formulation of azithromycin (Fig. 7a) at optimized concentration $(4 \mu \mathrm{g} / \mathrm{ml})$, the cells showed no morphological disturbances. Whereas, considerable morphological changes were observed with $S$. aureus-treated cinnamon oil-based microemulsion formulation of azithromycin at the same optimized concentration (Fig. 7b). The images obtained by scanning electron microscopy (SEM) demonstrated the presence of considerable distortion of the cell membrane when treated with microemulsion formulation at a minimum concentration.

\section{DISCUSSION}

Microemulsions serve as colloidal drug delivery agents for bioactive compounds of poorly soluble drugs with limited dissolution for use in pharmaceutical technology $(56,57)$. The selection of formulation components were based on GRAS category. Microemulsions are formed spontaneously when the interfacial tension between oil and water are reduced close to

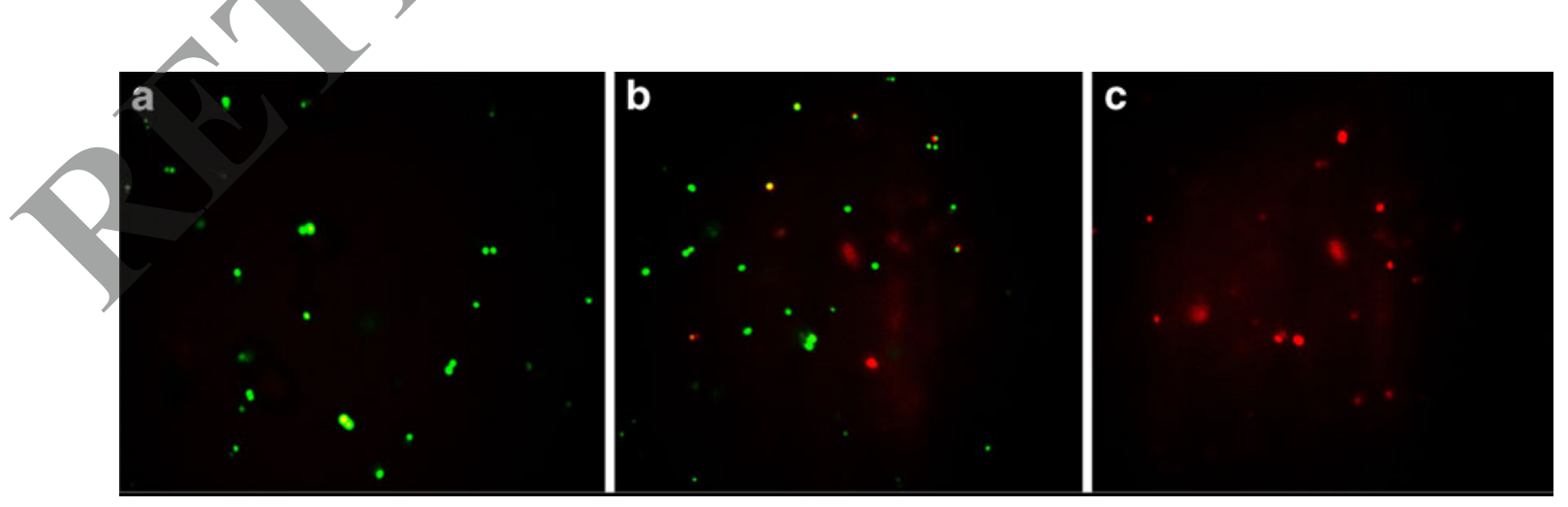

Fig. 6. Fluorescence micrograph of acridine orange/ethidium bromide-stained $S$. aureus cells. a Untreated (control) cells are green in color. b Conventional formulation of azithromycin-treated cells are also green in color at $4 \mu \mathrm{g} / \mathrm{ml}$ concentration. c Cinnamon oil microemulsion formulation-treated cells are red in color at the same concentration 

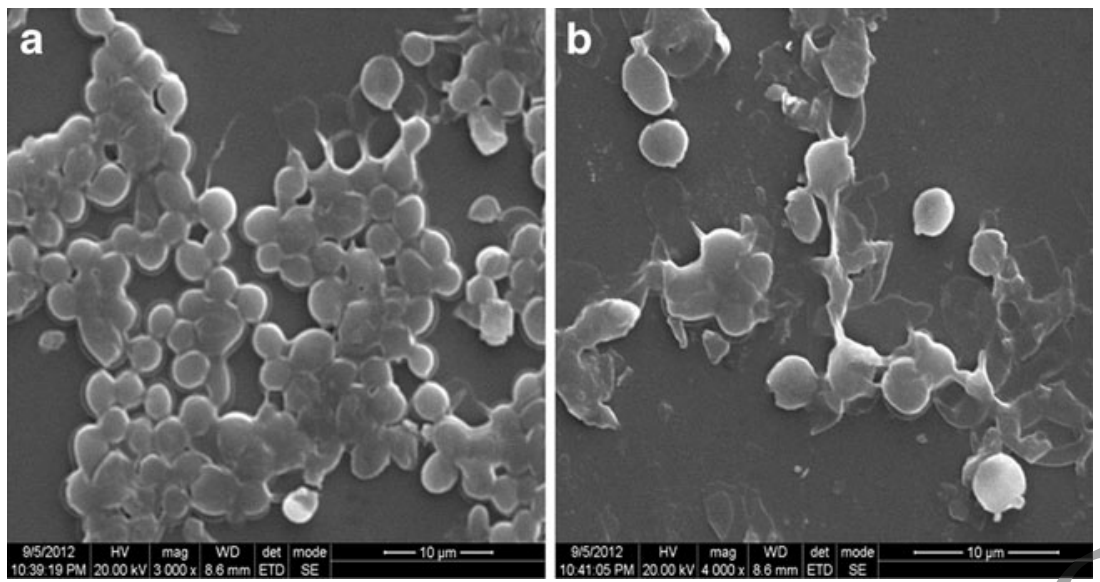

Fig. 7. Scanning electron microscopic images to identify the morphological changes of $S$. aureus-treated cells. a Treated cells with conventional formulation of azithromycin. b Treated cells with cinnamon oil microemulsion formulation of azithromycin showed significant morphological changes

zero (58). Surfactants play a major role in reducing the interfacial tension in microemulsions. In general, surfactants with low HLB value tend to form W/O microemulsion and those with high $\mathrm{HLB}$ vale forms $\mathrm{O} / \mathrm{W}$ microemulsion. In our azithromycin-incorporated formulations, initially, when the surfactant concentration was too low (F1, F2, and F3), phase separation occurred immediately. This demonstrates that stable emulsions could not be formed for these formulations and hence disqualified for further application. The F4 formulation demonstrated good thermodynamic stability with comparatively lower viscosity compared to F5, and thus F4 was considered as the best optimized formulation. One may also arouse a question whether our formulated system is microemulsion or nanoemulsion owing to the size range. The difference is from the historical definition rather than the size ranges. The critical difference between the two systems is that nanoemulsions are formed by mechanical shear and microemulsions are formed by self-assembly (59).

The stabilization of droplets in the formulated system (F4), ranging about $5-8 \mathrm{~nm}$ is attributed to the surfactant molecules that reduce the energy required for stable formation. The droplet size of all formulations was found inversely proportional to the oil-surfactant ratio (that is, the higher the concentration of surfactant, the smaller is the droplets formed) (60). Also, the surfactant concentration showed a positive correlation with viscosity and negative correlation with turbidity. The increase in viscosity may be due to the water molecules that are trapped into the cross-linking portions of the surfactant molecules (61). The decrease in turbidity with increase in surfactant concentration is attributed to the reduced droplet size on increase in the surfactant concentration. Thus, optically transparent emulsion system is obtained due to relatively weak scattering of emulsion droplets with minimized diameter $(62,63)$.

The formulated new system (F4) was tested for its antibacterial efficacy against $S$. aureus in comparison with its conventional formulation. The superior bactericidal activity of the formulated microemulsion is mainly due to two reasons. The cinnamon oil itself possesses good antimicrobial property, and thus, incorporation of the drug in the novel system in turn, had improved the antibacterial efficacy. In simple words, the enhanced antibacterial activity was clearly due to the combination effect of azithromycin and the emulsified cinnamon oil co-treatment and not just due to the azithromycin alone. Secondly, the droplet size reduction and thereby, enhanced droplet surface area is made available for its interaction with bacteria. The microemulsion system is capable of fusion with the lipid bilayer cell membrane of the pathogen. This results in destabilization of the membrane integrity and function, resulting in lysis and death of the organism (64). Thus, the changes in the membrane structure would have altered their permeability and therefore caused an increase in the leakage of UV absorbing substances. The membrane integrity test clearly demonstrates significant release of cytoplasmic contents from the cinnamon oil-based microemulsion system as compared to conventional formulation of azithromycin. The effect of structural damage of cell membrane was further confirmed by fluorescence technique. As fluorescence is endorsed with the property of acridine orange and ethidium bromide to intercalate with nucleic acids due to the lofty negative charge density of phosphate groups, sugars, and hydrogen bonding opening in DNA and RNA $(65,66)$. Further, the SEM images demonstrated clear distortion of the cell membrane on treatment with drug-loaded microemulsion system. This result can be correlated with another study (67), in that, they reported irregular boundary and unclear margins of cell membrane of cariogenic Streptococcus mutans upon treatment with soyabean oil emulsion with very small droplet-sized diameter. But, no considerable morphologic changes were seen in the conventional formulation of azithromycin at the same minimized optimum $(4 \mu \mathrm{g} / \mathrm{ml})$ concentration. Thus, the cinnamon oil-based microemulsion system of azithromycin exhibited substantial antibacterial activity against $S$. aureus.

\section{CONCLUSION}

The clear transparent, low viscous, thermodynamically stable, and the ease of preparation with no high-energy methods is an added advantage of this novel formulation to the pharmaceutical scientists. Our finding has reported the minimum droplet size of the drug-loaded microemulsion system of azithromycin that may enhance their permeation 
through capillary vessels. Also, the superior antibacterial activity of the cinnamon oil-based formulation F4 at a very minimum concentration, would in turn, reduce the dosage level of azithromycin and thereby, increasing the efficacy as a system to a greater extent. Yet, further confirmatory studies regarding this experiment are to be carried out using in vivo animal models to arrive at any final conclusion and the necessary steps are being carried out.

\section{ACKNOWLEDGEMENTS}

Authors thank the management of VIT University, Chancellor, for providing facility to carry out our research. We acknowledge Sophisticated Analytical Instrumentation Facility (SAIF), Department of Science \& Technology (DST) at Indian Institute of Technology (IIT), Madras, for Scanning Electron Microscopy facility used in our research.

\section{REFERENCES}

1. Crosseley KB, Archer GL. The staphylococci in human diseases. 1st ed. New York: Livingstone; 1997.

2. Ashley DJ, Brindle MJ. Penicillin resistance in staphylococci isolated in a casually department. J Clin Pathol. 1980;13:336-8.

3. Dinos GP, Michelinaki M, Kalpaxis DL. Insights into the mechanism of azithromycin interaction with an Escherichia coli functional ribosomal complex. Mol Pharmacol. 2001;59(6):1441-5.

4. Hoepelman IM, Schneider MME. Azithromycin; the first of the tissue-selective azalides. Int J Antimicrob Agents. 1995;5:145-67.

5. Mazzei T, Mini E, Novelli A, Periti P. Chemistry and mode of action of macrolides. J Antimicrob Chemother. 1993;31:1-9.

6. Barry AL, Thornsberry C, Jones RN. In vitro activity a new macrolide A-56268, compared with that of roxithromycin, erythromycin and clindamicin. Antimicrob Agents Chemother. 1987;31:343-5.

7. Retsema J, Girard A, Schelkly W, Manousos M, Anderson M, Bright G. Spectrum and mode of action of azithromycin (CP62.993), a new 15-membered-ring macrolide with improved potency against Gram negative organisms. Antimicrob Agents Chemother. 1987;31:1939-47.

8. Archer GL, Climo MW. Antimicrobial susceptibility of coagulase-negative staphylococci. Antimicrob Agents Chemother. 1994;38:2231-7.

9. Champney WS, Burdine R. Azithromycin and clarithromycin inhibition of 50S ribosomal subunit formation in Staphylococcus aureus cells. Curr Microbiol. 1998;36:119-23.

10. Hunter RP, Koch DE, Coke RL, Goatley MA, Isaza R. Azithromycin metabolism identification in plasma, bile, and tissues of the ball python (Python regius). J Vet Pharmacol Therap. $2003 ; 26.117-21$.

11. Chayani N, Tiwari S, Sarangi G, Mallick B, Mohapatra A, Paty BP, et al. Role of azithromycin against clinical isolates of family enterobacteriaceae: a comparison of its minimum inhibitory concentration by three different methods. Indian J Med Microbiol. 2009;27:107-10.

12. Luke DR, Foulds G. Disposition of oral azithromycin in humans. Clin Pharmacol Ther. 1997;61:641-8.

13. Arora SC, Sharma PK, Irchhaiya R, Khatkar A, Singh N, Gagoria J. Development, characterization and solubility study of solid dispersions of azithromycin dehydrate by solvent evaporation method. J Adv Pharm Technol Res. 2010;1(2):221-8.

14. Chen H, Chang X, Du D, Li J, Xu H, Yang X. Microemulsionbased hydrogel formulation of ibuprofen for topical delivery. Int $\mathrm{J}$ Pharm. 2006;315:52-8.

15. Yuan Y, Li S, Mo F, Zhong D. Investigation of microemulsion system for transdermal delivery of meloxicam. Int J Pharm. 2006;321:117-23.
16. Damasceno BP, Dominici VA, Urbano IA, Silva JA, Araújo IB, Santos-Magalhães NS, et al. Amphotericin B microemulsion reduces toxicity and maintains the efficacy as an antifungal product. J Biomed Nanotechnol. 2012;8:290-300.

17. Shah KA, Joshi MD, Patravale VB. Biocompatible microemulsions for fabrication of glyceryl monostearate solid lipid nanoparticles (SLN) of tretinoin. J Biomed Nanotechnol. 2009;5(4):396-400.

18. He CX, He ZJ, Gao JQ. Microemulsions as drug delivery systems to improve the solubility and bioavailability of poorly-water soluble drugs. Expert Opin Drug Deliv. 2010;7(4):445-60.

19. Fatouros DG, Karpf DM, Nielsen FS, Mullertz A. Clinical studies with oral lipid based formulations of poorly soluble compounds. Ther Clin Risk Manag. 2007;3:591-604.

20. Bagwe RP, Kanicky JR, Palla BJ, Patanjali PK, Shah DO. Improved drug delivery using microemulsions: rationale, recent progress and new horizons. Crit Rev Ther Drug. 2001;18:77-140.

21. Nagarajan R. Molecular theory of microemulsions. Langmuir. 2000;16:6400-15.

22. Talegaonkar S, Azeem A, Ahmad JF, Khar RK, Pathan SA, Khan ZI. Microemulsions: a novel approach to enhanced drug delivery. Recent Pat Drug Deliv Formul. 2008:2:238-57.

23. Hamidi M, Shahbazi MA, Rostamizadeh K. Copolymers: efficient carriers for intelligent nanoparticulate drug targeting and gene therapy. Macromol Biosci. 2012;12:144-64.

24. Mundargi RC, Babu VR, Rangaswamy V, Patel P, Aminabhavi TM. Nano/micro technologies for delivering macromolecular therapeutics using poly (D,L-lactide-co-glycolide) and its derivatives. J Control Release. 2008;125:193-209.

25. Mitra N, Mukhopadhya L, Bhattacharya P, Moulik SP. Biological microemulsions V: mutual mixing of oils, amphiphiles and water in tenary and quaternary combinations. Indian $\mathrm{J}$ Biochem Biophys. 1996;33:206-12.

26. Mitra N, Mukhopadhya L, Bhattacharya P, Moulik SP. Biological microemulsion IV: phase behavior and dynamics of microemulsions prepared with vegetable oils mixed with AOT, cinnamic alcohol and water. Indian J Biochem Biophys. 1996;31:115-20.

Acharya A, Sanyal SK, Moulik SP. Physicochemical investigations on microemulsification of eucalyptol and water in presence of polyoxyethylene (4) lauryl ether (Brij-30) and ethanol. Int J Pharm. 2001;229:213-26.

28. Acharya A, Moulik SP, Sanyal SK, Mishra BK, Puri PM. Physicochemical investigations of microemulsification of coconut oil and water using polyoxyethylene 2-cetyl ether (Brij-52) and isopropanol or ethanol. J Colloid Interface Sci. 2002;245:163-70.

29. Paul BK, Moulik SP. Biological microemulsions: part III. The formation characteristics and transport properties of saffolaAOT-hexylamine-water system. Indian J Biochem Biophys. 1991;28:174-83.

30. Gupta S, Moulik SP, Lala S, Basu M, Sanyal SK, Datta S. Designing and testing of an effective oil-in-water microemulsion drug delivery system for in vivo application. Drug Del. 2005;12:267-74.

31. Gupta S, Moulik SP, Hazra B, Ghosh R, Sanyal SK, Datta S. New pharmaceutical microemulsion system for encapsulation and delivery of a plant-derived bioactive quinonoid compound, diospyrin. Drug Del. 2006;12:193-9.

32. Lala S, Gupta S, Basu MK, Moulik SP. Critical evaluation of the therapeutic potential of basic acid entrapped in oil-in-water microemulsions and classical polylactide nanoparticles against leishmaniasis. J Drug Target. 2006;14:171-9.

33. Ping $\mathrm{H}$, Zhang G, Ren G. Anti-diabetic effects of cinnamon oil in diabetic KK-Ay mice. Food Chem Toxicol. 2010;48:2344-9.

34. Goni P, Lopez P, Sanchez C, Gomez-Lus R, Becerril R, Nerin C. Antimicrobial activity in the vapour phase of a combination of cinnamon and clove essential oils. Food Chem. 2009;116(4):982-9.

35. Matan N, Rimkeeree H, Mawson AJ, Chompreeda P, Haruthaithanasan V, Parker M. Antimicrobial activities of cinnamon and clove oils under modified atmosphere conditions. Int $\mathbf{J}$ Food Microbiol. 2006;107:180-5.

36. Tzortzakis NG. Impact of cinnamon oil-enrichment on microbial spoilage of fresh produce. Innovat Food Sci Emerg Tech. 2009;10:97-102.

37. Singh G, Maurya S, de Lampasona MP, Catalan CAN. A comparison of chemical, antioxidant and antimicrobial studies of cinnamon leaf and bark volatile oils, oleoresins and their constituents. Food Chem Toxicol. 2007;45:1650-61. 
38. Yu HS, Lee SY, Jang CG. Involvement of 5-HT(1A) and GABA(A) receptors in the anxiolytic-like effects of Cinnamonum cassia in mice. Pharmacol Biochem Behav. 2007;87:164-70.

39. Wang R, Wang R, Yang B. Extraction of essential oils from cinnamon leaves and identification of their volatile compound composition. Innovat Food Sci Emerg Tech. 2008;10:289-92.

40. Shafiq S, Shakeel F, Talegaonkar S, Ahmad FJ, Khar RK, Ali M. Design and development of oral oil in water ramipril nanoemulsion formulation: in vitro and in vivo assessment. J Biomed Nanotechnol. 2007;3:28-44.

41. Andrews JM. Determination of minimum inhibitory concentrations. J Antimicrob Chemother. 2001;48:5-16.

42. Bauer RW, Kirby MDK, Sherris JC, Turck M. Antibiotic susceptibility testing by standard single disc diffusion method. Am J Clin Path. 1966;45:493-6.

43. Veeramuthu D, Muniappan A, Ignacimuthu S. Antimicrobial activity of some ethnomedicinal plants used by Paliyar tribe from Tamil Nadu, India. BMC Complement Altern Med. 2006;6:35-41.

44. Park Y, Nao HJ, Han L, Kim HS, Kim YJ, Choi JS, et al. Artemisia capillaris extracts as a green factory for the synthesis of silver nanoparticles with antibacterial activities. J Nanosci Nanotechnol. 2012;12(9):7087-95.

45. Klancnik A, Piskernik S, Jersek B, Mozina SS. Evaluation of diffusion and dilution methods to determine the antibacterial activity of plant extracts. J Microbiol Methods. 2010;81:121-6.

46. Badiceanu CD, Larion C. Antimicrobial activity of some new thioureides from 2-thiopheneacetic acid. Farmacia. 2009;57(4):473-8.

47. Lucia A, Claudia M, Sara S, Elisa P, Marta P, Luis DV, et al. Antibacterial activity of extracts obtained from Senna corymbosa and Tipuana tipu. PhOL. 2012;3:158-61.

48. Hou L, Shi Y, Zhai P, Le G. Inhibition of food-borne pathogens by Hf-1, a novel antibacterial peptide from the larvae of the housefly (Musca domestica) in medium and orange juice. Food Control. 2007;18:1350-7.

49. Jakopec S, Dubravcic K, Polanc S, Kosmrlj J, Osmak M. Diazene JK-279 induces apoptosis-like cell death in human cervical carcinoma cells. Toxicol In Vitro. 2006;20:217-26.

50. Constantinides PP, Yiv SH. Particle size determination of phase inverted water-in-oil microemulsions under different dilution and storage conditions. Int J Pharm. 1995;115:22534.

51. Shinoda K, Saito H. The stability of O/W type emulsions as functions of temperature and the HLB of emulsifiers: the emulsification by PIT-method. J Colloid Interface Sci. 1969;30:258-63.

52. Barry AL, Thornsberry C, Gavan TL. Quality control parameters and interpretive criteria for in vitro susceptibility tests with the macrolide azithromycin. Collaborative Antimicrobial Susceptibility Testing Group. Eur J Clin Microbiol Infect Dis. 1989;8(6):544-9.

53. Navarro FP, Berger M, Guillermet S, Josserand V, Guyon L, Newmann E, et al. Lipid nanoparticle vectorization of indocyanine green improves fluorescence imaging for tumor diagnosis and lymph node resection. J Biomed Nanotechnol. 2012;8(5):730-41.

54. Saranya S, Nirmala MJ, Ghosh V, Anjali CH, Mukherjee A, Chandrasekaran N. Bio-based nanoemulsion formulation, characterization and anti-bacterial activity against food-borne pathogens. J Basic Microbiol. 2012;52:1-10.

55. Stokes DJ. Recent advances in electron imaging, imaging interpretation and applications: environmental scanning electron microscopy. Phil Trans R Soc London Ser A. 2003;361:2771-87.

56. Lawrence MJ, Rees GD. Microemulsion-based media as novel drug delivery systems. Adv Drug Deliv Rev. 2000;45:89-121.

57. Gupta S. Biocompatible microemulsion systems for drug encapsulation and delivery. Curr Sci. 2011;101:174-88.

58. Tadros T, Izquierdo P, Esquena J, Solans C. Formation and stability of nano-emulsions. Adv Colloid Interface Sci. 2004;108-109:303-18.

59. Mason TG, Wilking JN, Meléson K, Chang CB, Graves SM. Nanoemulsions: formation, structure, and physical properties. J Phys Condens Matter. 2006;18:R635-66.

60. Ghosh V, Mukherjee A, Chandrasekaran N. Ultrasonic emulsification of food-grade nanoemulsion formulation and evaluation of its bactericidal activity. Ultrason Sonochem. 2013;20:338-44.

61. Eini DIDE, Barry BW, Rhodes CT. Micellar size, shape and hydration of long-chain polyoxyethylene nonionic surfactants. J Colloid Interface Sci I. 1976;54:348.

62. McClements DJ. Colloidal basis of emulsion color. Curr Opin Colloid Interface Sci. 2002;7:451-5.

63. McClements DJ. Theoritical prediction of emulsion color. Adv Colloid Interface Sci. 2002;97:63-89.

64. Baker JR, Hamouda T, Shih A, Andrzej M. Non-toxic antimicrobial compositions and methods of use. US Patent. 2003;6:559,189.

65. Lauretti F, Melo FL, Benati FJ, Volotão EM, Santos N, Linhares REC, et al. Use of acridine orange staining for the detection of rotavirus RNA in polyacrylamide gels. J Virol Methods. 2003;114:29-35.

Nafisi S, Saboury AA, Keramat N, Neault JF, Tajmir-Riahi HA. Stability and structural features of DNA intercalation with ethidium bromide, acridine orange and methylene blue. J Mol Struct. 2007;827:35-43.

67. Dalai S, Pakrashi S, Kumar RS, Chandrasekaran N, Mukherjee A. A comparative cytotoxicity study of $\mathrm{TiO}_{2}$ nanoparticles under light and dark conditions at low exposure concentrations. Toxicol Res. 2012;1:116-30.

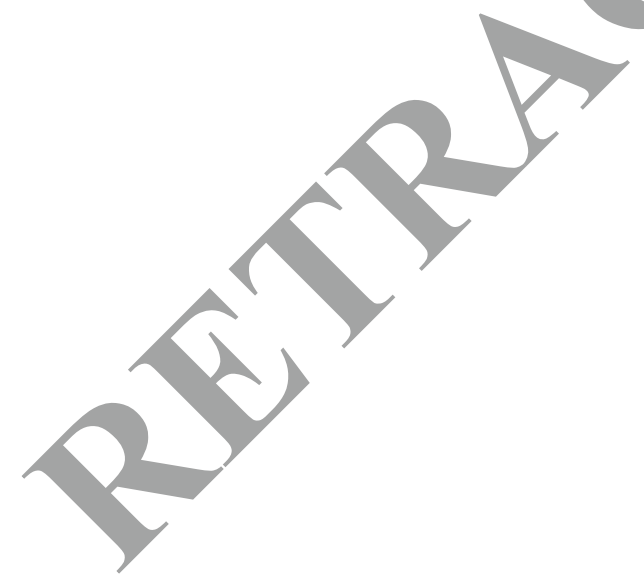

